\title{
Heat, Mass and Aerosol Transfers in Spray Conditions for Containment Application*
}

\author{
Emmanuel PORCHERON ${ }^{* *}$, Pascal LEMAITRE ${ }^{* *}$, \\ Amandine NUBOER $^{* *}$ and Jacques VENDEL ${ }^{* *}$ \\ "Institut de Radioprotection et de Sûreté Nucléaire (IRSN) \\ BP 68, 91192 Gif-sur-Yvette cedex, France \\ emmanuel.porcheron@irsn.fr
}

\begin{abstract}
TOSQAN is an experimental program undertaken by the Institut de Radioprotection et de Sûreté Nucléaire (IRSN) in order to perform thermal hydraulic containment studies. The TOSQAN facility is a large enclosure devoted to simulating typical accidental thermal hydraulic flow conditions in nuclear Pressurized Water Reactor (PWR) containment. The TOSQAN facility, which is highly instrumented with non-intrusive optical diagnostics, is particularly adapted to nuclear safety CFD code validation. The present work is devoted to studying the interaction of a water spray injection used as a mitigation means in order to reduce the gas pressure and temperature in the containment, to produce gases mixing and washout of fission products. In order to have a better understanding of heat and mass transfers between spray droplets and the gas mixture, and to analyze mixing effects due to spray activation, we performed detailed characterization of the two-phase flow.
\end{abstract}

Key words: Thermal Hydraulic, TOSQAN, Spray, Heat and Mass Transfers, Aerosol

\section{Introduction}

During the course of a hypothetical severe accident in a Pressurized Water Reactor (PWR), hydrogen may be produced by the reactor core oxidation and can be distributed into the reactor containment by convection flows and steam condensation on walls. In order to assess the risk of detonation generated by a high local hydrogen concentration, the hydrogen distribution in the containment has to be known. In addition, core degradation leads to fission products release into the containment. The most important part of the fission products is emitted in the particulate form (size close to $1 \mu \mathrm{m}^{(1)}$ ). They are mixed with aerosol resulting from degradation of structural materials such as control rods, ducts, for which granulometry is lower than $100 \mu \mathrm{m}$, with a material average density of $3 \mathrm{~g} . \mathrm{cm}^{-3}$. Only a fraction of the formed aerosol with a granulometry ranging below $5 \mu \mathrm{m}$ may migrate from the primary circuit towards the containment. Water spraying in the containment is used as a mitigation means in order to reduce pressure, to remove fission products and to enhance the gas mixing in case of the presence of hydrogen. The TOSQAN experimental program has been created to simulate typical thermal hydraulic conditions representative of a severe accident in the reactor containment. The specificity of the TOSQAN facility is characterized by a high level of instrumentation that provides detailed information on local and non-intrusive characterization of the two-phase flow for CFD codes validation ${ }^{(2)}$. The present work is devoted to studying the effect of a water spray activation used as a mitigation means in order to reduce steam containment pressure, to decrease the local 
hydrogen concentration by the mixing caused by spray entrainment and steam condensation on droplets, and to washout aerosol to the sump. In order to have a better understanding of physical phenomena, a detailed characterization of the spray and the gas is needed. Spray tests are performed in hot conditions to analyze the heat and mass transfers between spray droplets and gas mixtures composed of air and steam, or dry air, and the aerosol washout. In this paper, we present the analysis of water spray interaction with gaseous mixtures composed of air and steam, seeded with aerosol, in order to study, on the first hand, the heat and mass transfers between droplets and gas and, on the other hand, the aerosol removal processes by spray. This work is divided into three parts. The first part is devoted to present the TOSQAN facility, the instrumentation used and its principles. In the second part, an analysis of spray interaction with the air and steam mixture is performed. In the third part, we focus on the aerosol washout and we determine the aerosol collection efficiency for single droplet and for the global spray.

\section{The TOSQAN experimental facility}

\subsection{The TOSQAN vessel}

The TOSQAN facility shown in Fig. 1 consists of a closed cylindrical vessel $\left(7 \mathrm{~m}^{3}\right.$ volume, $4 \mathrm{~m}$ high, $1.5 \mathrm{~m}$ internal diameter) into which steam is injected.

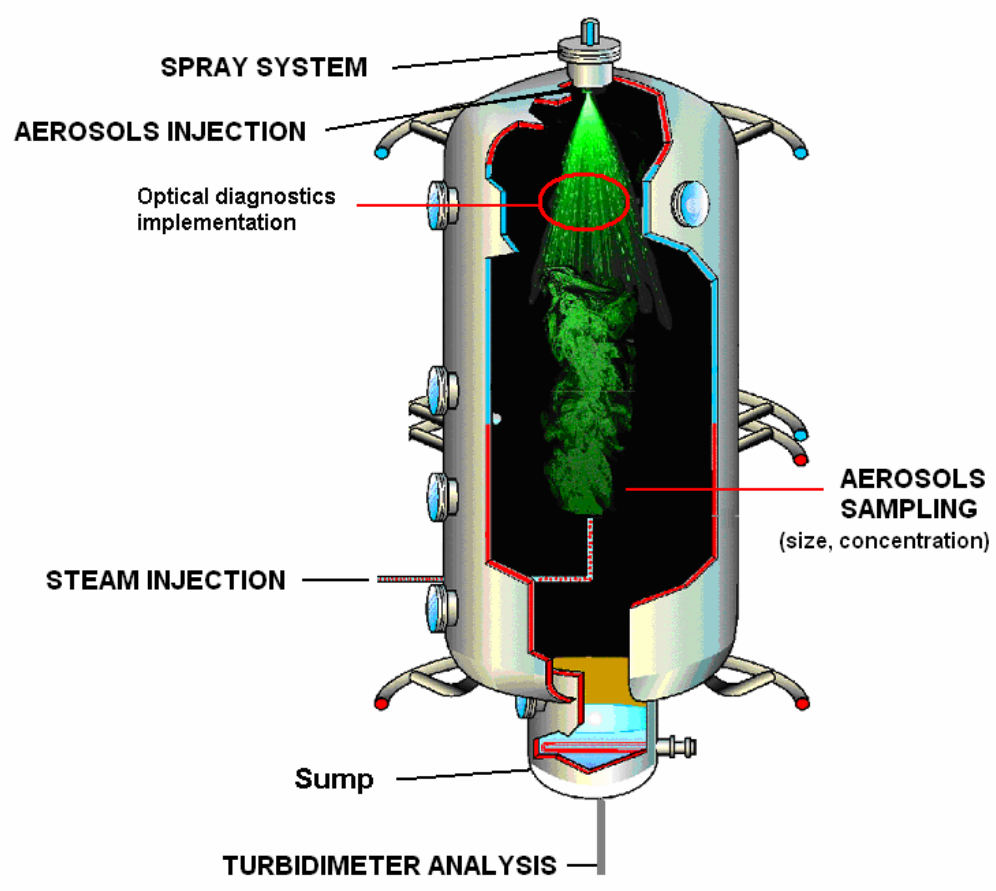

Fig.1 Overview of the TOSQAN facility

The walls of the vessel are thermostatically controlled by heated oil circulation to control the gas temperature inside the vessel. Optical accesses are provided by 14 pressure resistant viewing windows permitting non-intrusive optical measurements along orthogonal enclosure diameters. The inner spray system, located in the dome of the enclosure on the vertical axis, is composed of a single nozzle producing a full cone water spray. This nozzle is mobile along the vertical axis so that measurements can be made at different distances 
from the nozzle in order to be able to precisely mesh the close field of the spray injection. Aerosol, which are used for fission products simulation, are injected into the top of the dome of the vessel by the means of a powder spreader.

\subsection{Instrumentation}

Both intrusive and non-intrusive techniques are implemented on the TOSQAN facility in order to achieve a detailed characterization of the spray droplets, aerosol and the gas.

\subsubsection{Description of intrusive techniques}

Over 100 thermocouples are used to measure the gas temperature in the whole vessel. Thermocouples are located along the vessel diameter at 6 different levels distributed along the TOSQAN height. Other thermocouples are located in the sump and dome regions, and near the heated walls. The mass spectrometry technique is used for gas concentrations measurements. The sampling system is composed of 9 heated lines, each connected via a rotating valve to 6 fine tubes which provide 54 sampling points located at different heights and radii ${ }^{(3)}$. Aerosol mass concentration $\left(\mathrm{C}_{\text {aerosol }}(0)\right)$ and size distribution $\left(\mathrm{D}_{\text {aerosol }}\right)$ in the gas phase are measured, during the test, using an optical granulometer ${ }^{(4)}$. Aerosol sampling is realized in the spray region. The water which is drained out of the vessel at the sump level is analyzed using a prototype online turbidimeter, in order to determine the aerosol mass $\left(\mathrm{M}_{\text {aerosol_collected }}\right)$ collected by droplets during their fall (Fg.1). Because the water spray falling into the sump is removed with the same injected water mass flow, there is no water accumulation in the sump, and therefore it is empty during all along the test.

\subsubsection{Description of non-intrusive techniques}

Droplets velocity measurements are performed with two kinds of commercial optical diagnostics such as the Particle Image Velocimetry technique (PIV) and Laser Doppler Velocimetry technique (LDV). Both techniques are based on Mie scattering derived by the light generated by the interaction between particles (water droplets or seeding) and a laser beam. The LDV technique provides local information on the Turbulence Intensity (TI) and on the two velocity components, the vertical one (V) and the radial one (U) (Table 1). The PIV technique provides instantaneous or mean velocity fields of the flow (Table 1). Various kinds of measurement techniques are available for analyzing the spray droplets size distribution, such as the Phase Doppler Anemometry (PDA). The PDA ${ }^{(5)}$ technique cannot be used in the TOSQAN facility because of optical access constraints. This is why we decided to use the Interferometrics Laser Imaging for Droplet Sizing (ILIDS) ${ }^{(6)}$. For gas volume fraction measurements, we use the Spontaneous Raman Scattering spectroscopy $(\mathrm{SRS})^{(7)}$. The accuracy of the instrumentation used on the TOSQAN facility is detailed in the quoted references and is summarized in Table 1. 
Table 1. TOSQAN instrumentation accuracy

\begin{tabular}{|c|c|c|c|}
\hline & Techniques & Physical magnitude & Accuracy \\
\hline \multirow[t]{3}{*}{ Droplets } & LDV & $\begin{array}{c}\mathrm{V}, \mathrm{U}(\mathrm{m} / \mathrm{s}) \\
\mathrm{TI} \\
\end{array}$ & $1 \%$ to $5 \%$ \\
\hline & PIV & $\mathrm{V}, \mathrm{U}(\mathrm{m} / \mathrm{s})$ & $2 \%$ to $10 \%$ \\
\hline & ILIDS & $\mathrm{D}_{\text {droplet }}(\mu \mathrm{m})$ & $5 \%$ \\
\hline \multirow{3}{*}{ Gas } & SRS & $X_{\text {steam }}, X_{\text {air }}(\%)$ & $+/-1 \mathrm{Vol} \%$ \\
\hline & Mass spectrometry & $X_{\text {steam }}, X_{\text {air }}(\%)$ & $+/-1.5 \mathrm{Vol} \%$ \\
\hline & Thermocouple & $\mathrm{T}\left({ }^{\circ} \mathrm{C}\right)$ & $+/-1^{\circ} \mathrm{C}$ \\
\hline \multirow[t]{2}{*}{ Aerosol } & $\begin{array}{r}\text { Optical } \\
\text { spectrometer }\end{array}$ & $\begin{array}{c}\mathrm{D}_{\text {aerosol }}(\mu \mathrm{m}) \\
\mathrm{C}_{\text {aerosol }} \\
\left(\mathrm{mg} / \mathrm{m}^{3}\right)\end{array}$ & $\begin{array}{c}0.01 \mu \mathrm{m} \\
5 \%\end{array}$ \\
\hline & Turbidimeter & $\mathrm{M}_{\text {aerosol_collected }}(\mathrm{mg})$ & $7 \%$ \\
\hline
\end{tabular}

\subsection{Test procedure}

Test scenario consists in water spray injection in the TOSQAN vessel that is initially seeded with aerosol simulating fission products release, and after, pressurized with steam, simulating the primary circuit breach (Table 2). Aerosols are initially injected into the vessel which has a gas leak in order to stay at atmospheric pressure during the aerosols injection phase. Aerosol concentration in suspension in the vessel is measured in real time by using the WELAS granulometer that allows good reproductibility of the initial test conditions. This measurement is also used to determine the total aerosol mass present in the gas of the vessel all along the test and particularly just before the spray activation, since it is not able to measure accurately the aerosol mass injected in the vessel. The aerosol chosen for this study are particles of silicon carbide ( $\mathrm{SiC}$ ) with a granulometry ranging below $5 \mu \mathrm{m}$ and material density of 3.2 g. $\mathrm{cm}^{-3}$ (see Table 3 ). The spray nozzle used is fed with a water mass flow rate equal to $30 \mathrm{~g} / \mathrm{s}$ and a water temperature equal to $20^{\circ} \mathrm{C}$. However, at the beginning of the spray activation ( $\mathrm{t}<30 \mathrm{~s}$ ), the temperature of the water injected is above $30^{\circ} \mathrm{C}$ because the water which is initially present in the spray circuit is heated by conduction from the vessel. The heated walls of the TOSQAN vessel are also fixed at the same temperature all along the tests $\left(120^{\circ} \mathrm{C}\right)$.

Table 2. Spray specifications

\begin{tabular}{|c|c|c|c|}
\hline $\begin{array}{c}\text { Water } \\
\text { injection } \\
\text { temperature }\end{array}$ & $\begin{array}{c}\text { Droplets } \\
\text { arithmetic mean } \\
\text { diameter }\left(\mathrm{D}_{\text {droplet }}\right)\end{array}$ & air & Gas mixture composition (bar) \\
\cline { 3 - 4 } & $146 \mu \mathrm{m}$ & 1 & 1.5 \\
\hline $20^{\circ} \mathrm{C}$ & & 1 & steam \\
\hline
\end{tabular}

Table 3. Aerosol specifications

\begin{tabular}{|c|c|c|c|}
\hline $\begin{array}{l}\text { Aerosol } \\
\text { type }\end{array}$ & $\begin{array}{c}\text { Initial } \\
\text { aerosol size } \\
(\mu \mathrm{m})\end{array}$ & $\begin{array}{c}\text { Initial } \\
\text { aerosol } \\
\text { standard } \\
\text { deviation }\end{array}$ & $\begin{array}{c}\text { Aerosol mass } \\
\text { injected }(\mathrm{mg})\end{array}$ \\
\hline $\mathrm{SiC}$ & 2 & 1.5 & 1800 \\
\hline
\end{tabular}




\subsection{Spray characterization}

Water spray is produced by a nozzle (TG_3.5) from Spraying System, with an internal diameter of $1 \mathrm{~mm}$ ), which produces droplets of an almost uniform size. Spray characterization has been performed by the means of optical diagnostics in order to determine the initial droplets velocity, droplets size and spray angle. The spray angle is an important parameter because we have to check that droplets do not reach the vertical heated wall of the TOSQAN vessel, in order to prevent droplets vaporization. The spray angle was determined using the laser visualization technique as shown in Fig.2. An example of droplets size measurement performed by ILIDS technique is presented in Fig.3. ILIDS measurements were not performed close to the nozzle exit because of the high droplets density which causes multi-scattering phenomena and droplets overlapping. The mean vertical and radial velocities of droplets measured close to the nozzle exit by the PIV technique are presented in Fig.4 and Fig.5. In both velocity fields, the spray nozzle is located at a height $(\mathrm{z})$ equal to $100 \mathrm{~mm}$. The reference for the vertical velocity is negative for falling droplets. In Fig.4, the shear layer between the gas and the spray in the vertical velocity field resulting from the momentum exchange between the two phases of the flow can be observed. The radial velocity field shown in Fig.5 shows a usual pattern of spray expansion due to droplets inertia, with the radial velocity component close to zero in the center-part of the spray. Others droplets velocity measurements were performed in the field remote from the nozzle exit, in order to obtain a vertical profile of droplets velocities (Fig.6), and radial profiles of droplets velocities at different distances from the nozzle (Fig.7). Droplet velocity measurements cannot be performed very close to the nozzle exit, which is the primary atomization zone with liquid ligaments. The initial droplets standardized velocity measured at $20 \mathrm{~mm}$ from the nozzle exit is therefore about $12 \mathrm{~m} / \mathrm{s}$. A characteristic flat velocity profile can be observed at $50 \mathrm{~mm}$ from the nozzle exit. This kind of profile which delimits the spray area is typical of the near field of spray where the penetration of gas inclusions within the liquid core is not very efficient due to the high droplets density ${ }^{(8)}$. At the spray periphery a counter-flow loop shown by a positive velocity can be distinguished. On the other radial profiles, the spray development in relation to the distance from the nozzle exit can be observed, showing a decrease in droplets velocity resulting from momentum exchange with the gas.

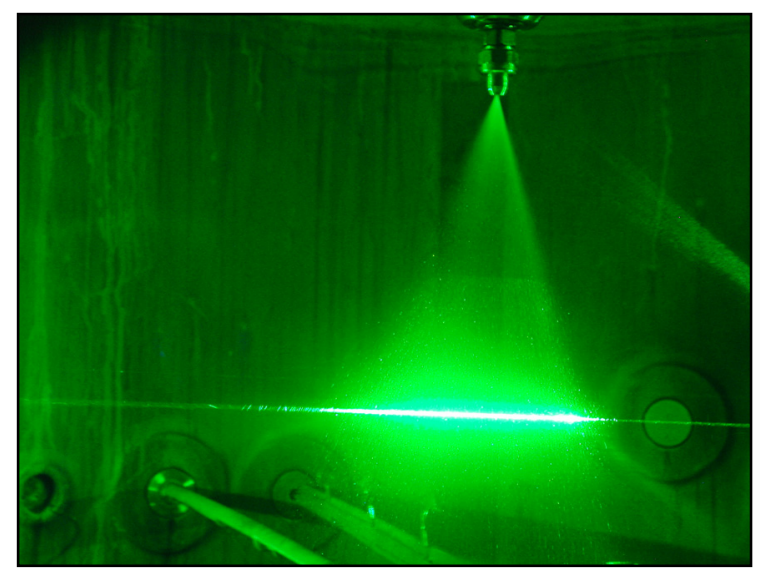

Fig.2 Spray visualization in the TOSQAN vessel 


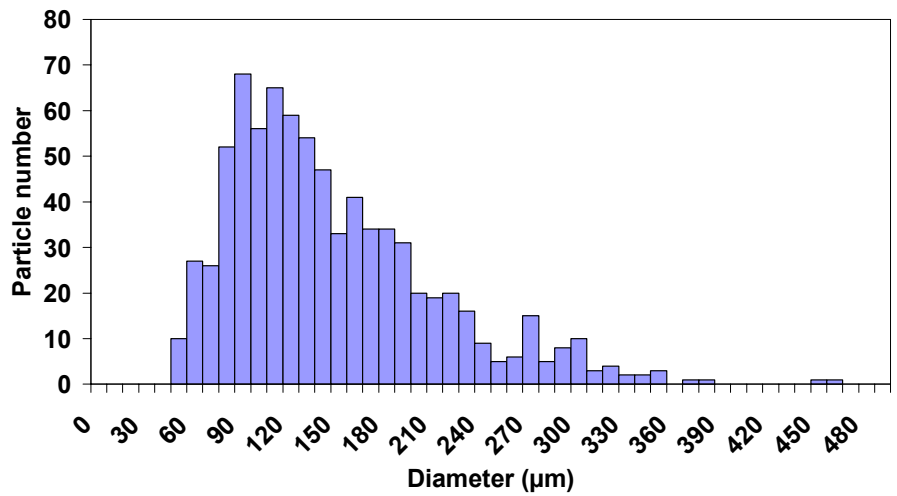

Fig.3 Droplets size distribution (ILIDS measurements performed at $1 \mathrm{~m}$ from the nozzle exit) - Arithmetic mean diameter value equal to $146 \mu \mathrm{m}$

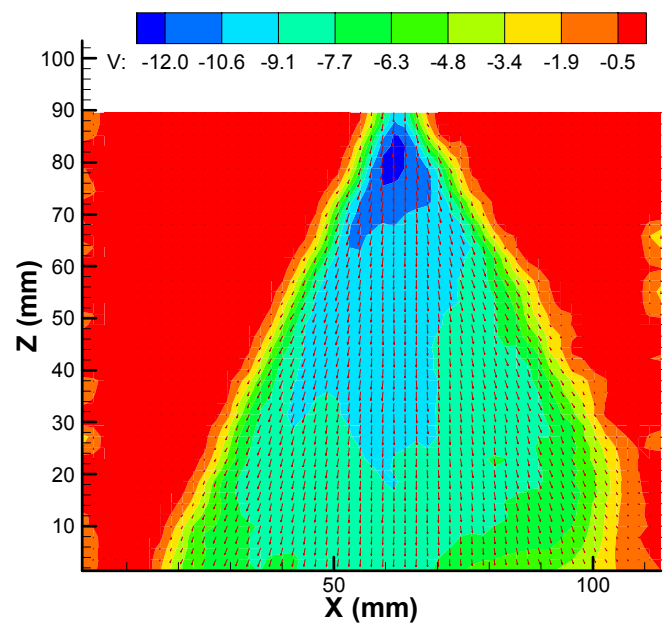

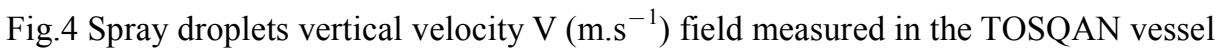

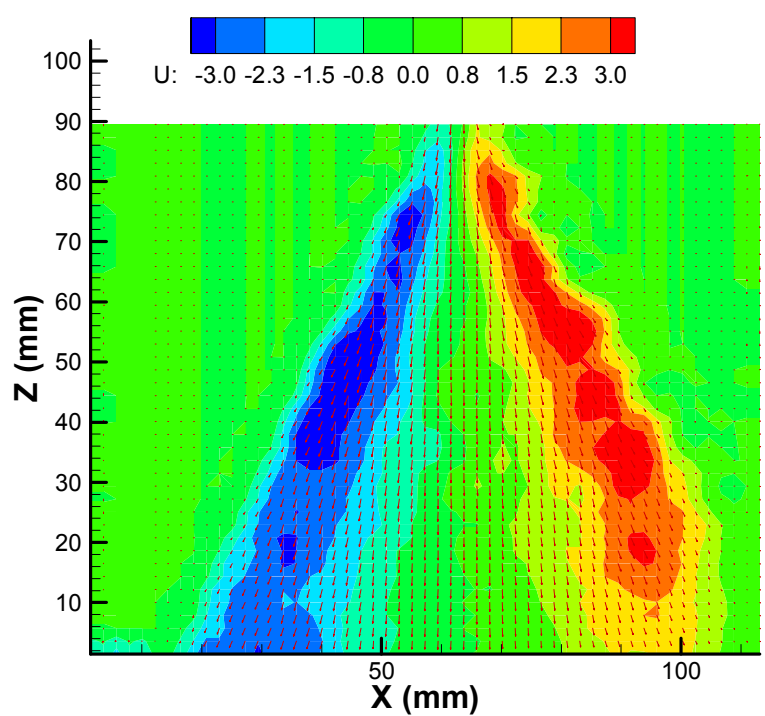

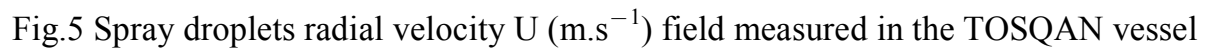




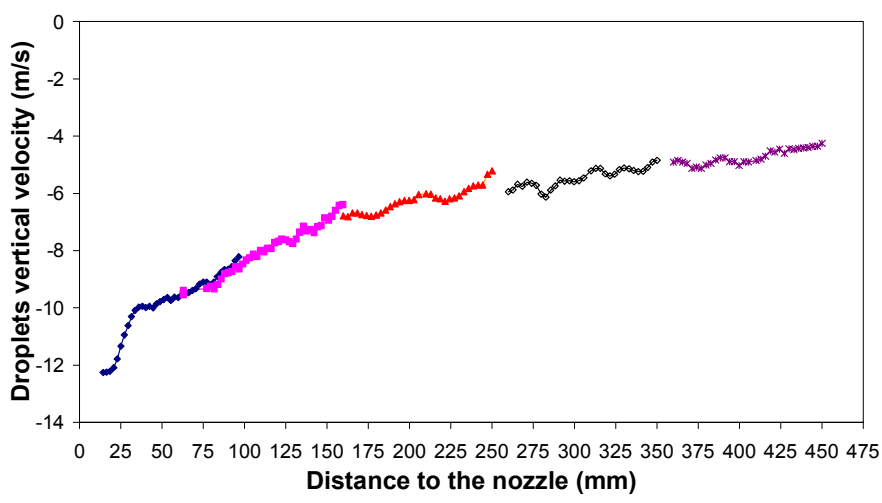

Fig.6 Spray droplets vertical velocity measured on vertical profile in the TOSQAN vessel (extracted from PIV measurements)

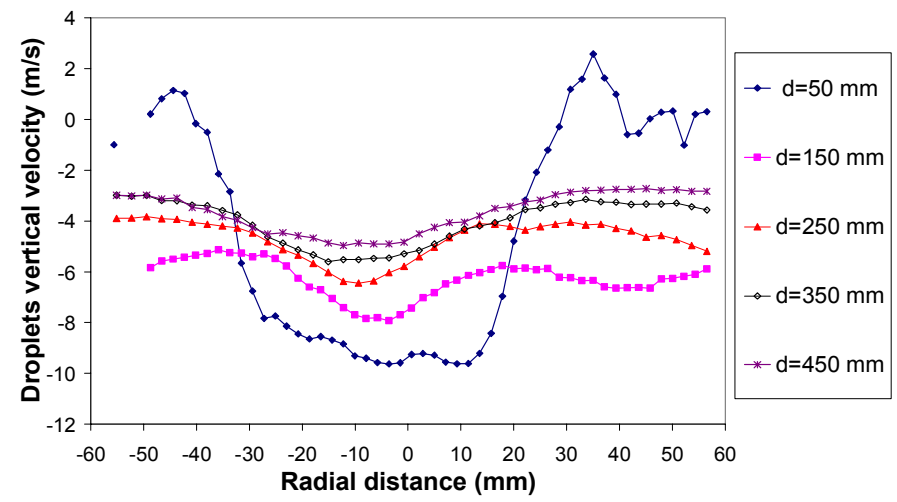

Fig.7 Spray droplets vertical velocity measured on radial profiles in the TOSQAN vessel (extracted from PIV measurements)

\section{Analysis of spray interaction with gas mixture}

We made an overall analysis of the test conducted with the air and steam mixture. Time evolutions of vessel relative pressure and mean gas temperature are shown in Fig.8. Steam injection is started at the time reference $t=-500 \mathrm{~s}$. The reference time $\mathrm{t}=0 \mathrm{~s}$ corresponds to spray activation. The mean gas temperature is the spatial average of gas temperatures measured with thermocouples located along the vessel diameter at 6 different levels distributed along the TOSQAN height. Gas temperature fields measured at different times during the test are shown in Fig.9 and Fig.10. The global Saturation Ratio SR(t), the steam saturated pressure $P_{\text {saturation }}(t)$ and the gas mole number $n_{\text {gas_moles }}(t)$ present in the vessel are computed in relation to time using Eq. (1), Eq. (2) and Eq. (3) for the test. The results are plotted in Fig. 11.

$$
S R(t)=\frac{P_{\text {steam }}(t)}{P_{\text {saturation }}(t)}
$$

With $P_{\text {steam }}(t)=P_{T O S Q A N_{-} \text {relative }}(t)$ 
The steam saturated pressure can be expressed with the following expression ${ }^{(9)}$.

$$
P_{\text {saturation }}(t)=\frac{10^{5}}{760} 10^{A}
$$

$$
\begin{aligned}
& \text { With } A=16.37-\frac{2818}{T_{\text {gas_mean }}(t)}-1,69 \log T_{\text {gas_mean }}(t) \\
& -5,75.10^{-3} \cdot T_{\text {gas_mean }}(t)+4,01.10^{-6} T_{\text {gas_mean }}^{2}(t) \\
& n_{\text {gas_moles }}(t)=\frac{P_{T O S Q A N \_ \text {relative }}(t) \cdot V_{T O S Q A N}}{R \cdot T_{\text {gas_mean }}(t)}
\end{aligned}
$$

Where, $T_{\text {gas_mean }}(t)$ is the mean gas temperature in the TOSQAN vessel, $P_{\text {steam }}(t)$ is the steam partial pressure and $P_{\text {TOSQAN_relative }}(t)$ is the relative pressure in the vessel, in relation to time $\mathrm{t}$.

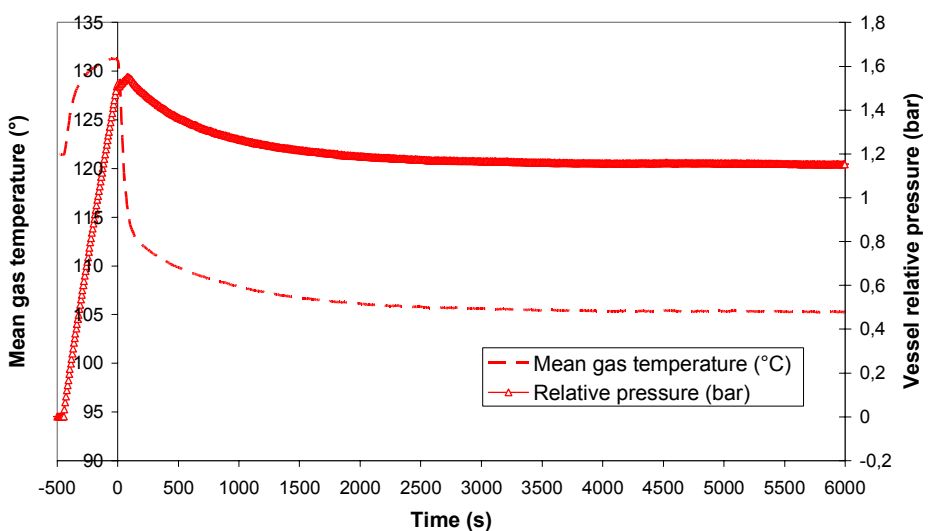

Fig. 8 Time evolutions of vessel relative pressure and mean gas temperature during the tests (spray is activated at $\mathrm{t}=0 \mathrm{~s}$ )

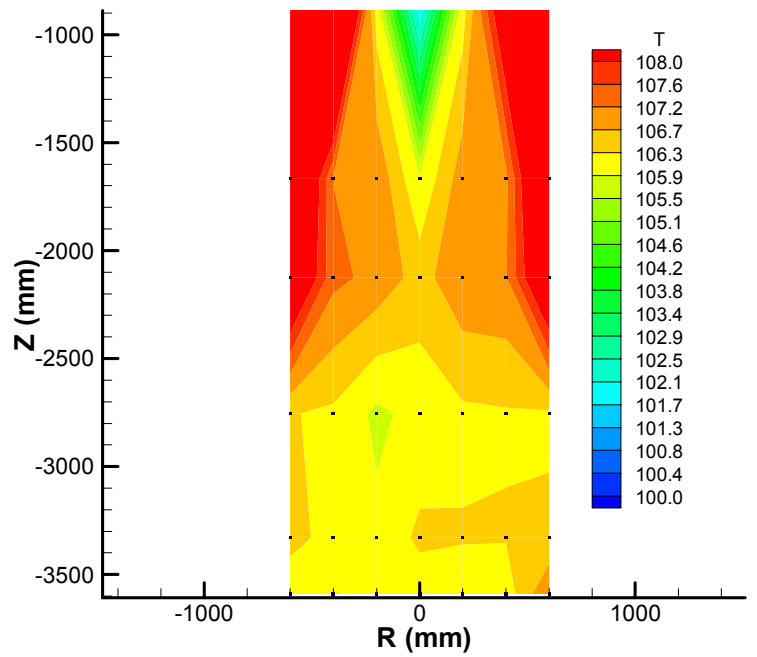

Fig.9 Gas temperature $\left({ }^{\circ} \mathrm{C}\right)$ field in the TOSQAN vessel measured at $\mathrm{t}=300 \mathrm{~s}$ 


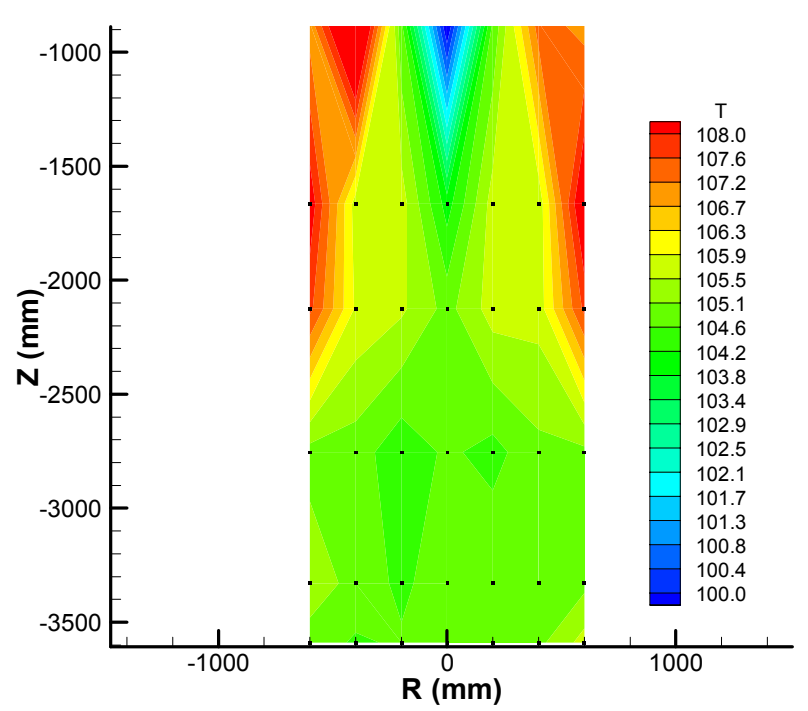

Fig. 10 Gas temperature $\left({ }^{\circ} \mathrm{C}\right)$ field in the TOSQAN vessel measured at $\mathrm{t}=3000 \mathrm{~s}$

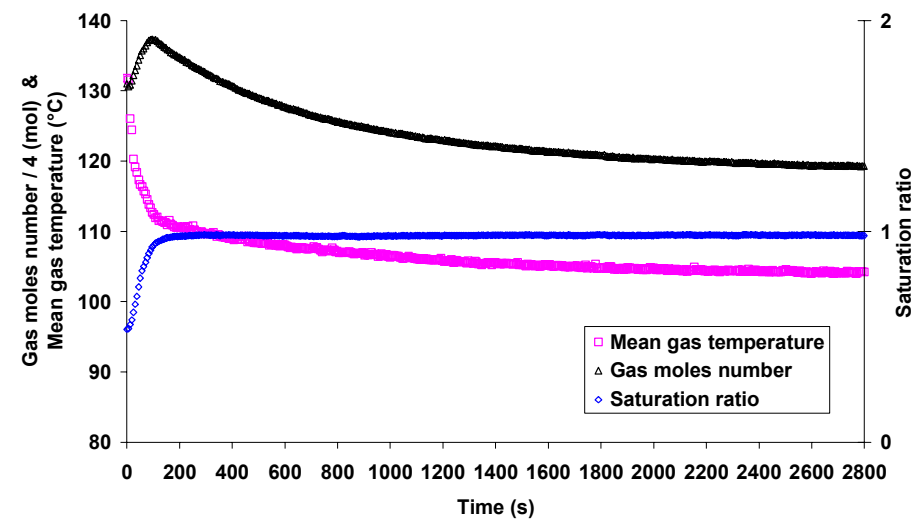

Fig.11 Time evolutions of Saturation Ratio, gas mole number and mean gas temperature

According to the results presented in the Fig.11, the test can be decomposed in different significant phases. At the beginning of spray activation $(0 \mathrm{~s}<\mathrm{t}<100 \mathrm{~s})$, a strong decrease of the vessel mean gas temperature, correlated with an increase in the saturation ratio, was observed. Spray activation is also followed by an initial overpressure generated by the increase of the gas mole number present in the vessel as shown in Fig.11. We can therefore conclude that during this time, spray droplets are vaporizing and therefore produce a steam source. During this phase, the mean gas temperature is above that of the heated walls temperature $\left(120^{\circ} \mathrm{C}\right)$ leading to the activation of the heat exchanger that controls the wall temperature. But this effect on the decrease in mean gas temperature is slight compared to that produced by the spray activation. At the end of this phase $(t=100 \mathrm{~s})$, the saturation ratio is practically at its equilibrium value equal to 1 , meaning that the gas mixture is almost saturated with steam. The second phase of the test is characterized by a strong decrease in the vessel pressure, gas mole number and mean gas temperature. During this phase $(t>100 \mathrm{~s})$, steam condensation on water droplets is the dominant phenomenon. The gas mixture is cooled by convective heat transfer with the droplets initially injected at $20^{\circ} \mathrm{C}$ that induces steam condensation on droplets in order to keep a saturated mixture. The cooling effect of the spray is clearly shown in Fig.9 that also shows the non-uniformity of the gas field in the vessel. 
The third phase of the test is characterized by a steady state with no significant changes in pressure, gas mole number, saturation ratio and mean gas temperature $(t>2500 \mathrm{~s})$. The gas temperature field given in Fig.10 shows a homogeneous pattern except near the vertical heated walls and in the spray area. The decrease in the gas temperature scatter, compared to that observed for the first phase, is the consequence of the renewal of the gas, caused by the circulation loop resulting from the spray entrainment. During this phase, the energy provided to the droplets by the gas is compensated by that provided by the heated walls to the gas.

\section{Study of aerosol removal by spray}

In this section we focus on the aerosol behaviour during the spray injection. During all the test, aerosol concentration and aerosol size present in the gas are measured in real time using optical granulometer ${ }^{(10)}$. From the time where the spray is activated, the aerosol mass collected by the spray droplets is also measured in real time. For this test, according to the spray angle, droplets don't impact the vertical walls of the vessel. So, we consider that the aerosol mass issued from the water drained along the vertical walls is negligible. For all the results presented on the following curves, the spray activation corresponds to the time $\mathrm{t}=0 \mathrm{~s}$. Time evolution of aerosol diameter is presented in Fig.12. In this figure is also presented the time evolution of aerosol number for different ranges of size. Spray activation induces a strong decrease of the aerosol mean diameter according to the mechanical effects $^{(11)}$ and phoretic effects ${ }^{(12)}$ involved in the removal of aerosol from the containment atmosphere by spray droplets. We can notice that the aerosol mean diameter decrease is more marked during the first two phases of the tests defined from Fig.11. Actually, for $\mathrm{t}<2500 \mathrm{~s}$, the aerosol removal process is more efficient for the largest aerosol which are collected by droplets, mainly due to mechanical effects. Phoretic effects such as diffusiophoresis are relative to steam concentration gradient around the droplets. Diffusiophoresis will play a part in the removal process during the phase of the test where heat and mass transfers between droplets and gas, such as steam condensation on droplets, are strong. So, at $\mathrm{t}=2500 \mathrm{~s}$, according to sedimentation, aerosol collection by droplets due to mechanical effects and subsidiarily, due to diffusiophoresis, aerosol which diameter is larger than $2 \mu \mathrm{m}$ are not present in the gas anymore.

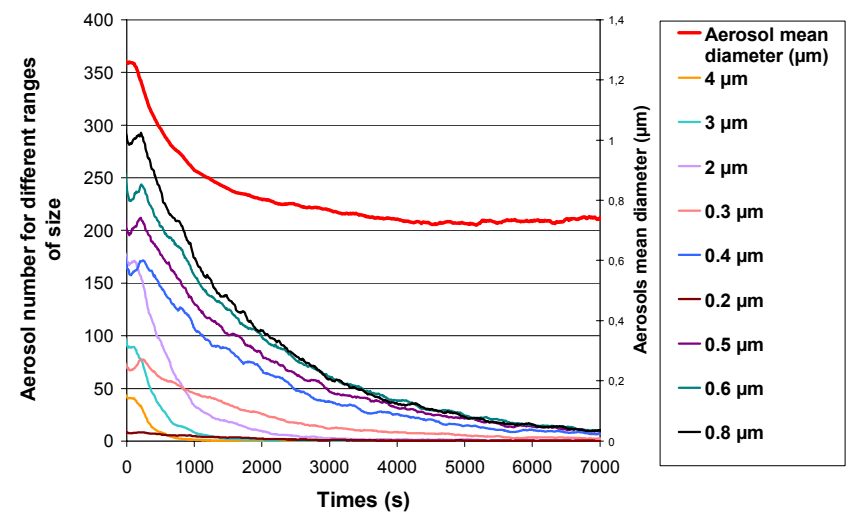

Fig.12 Time evolution of the aerosol mean diameter and aerosol number by range of size

In order to analyse the global spray collection efficiency as a function of aerosol size distribution, aerosol histograms size obtained at different times, before and during spraying, 
are presented in Fig.13. The global spray efficiency for aerosol removal, which is the ratio between the difference of the particles number present in the gas before spraying and at $\mathrm{t}=4000 \mathrm{~s}$, with the particles number present before spraying, is also plotted in Fig. 13. The global spray collection efficiency tends toward 1 for aerosol which size is larger than $1 \mu \mathrm{m}$. As we can see the global spray efficiency seems to have a minimum for aerosol size around $0.5 \mu \mathrm{m}$. This result corresponds to the fact that, for these ranges of aerosol and droplets size, mechanical effects have a poor efficiency and thermophoresis effects become negligible ${ }^{(13)}$.

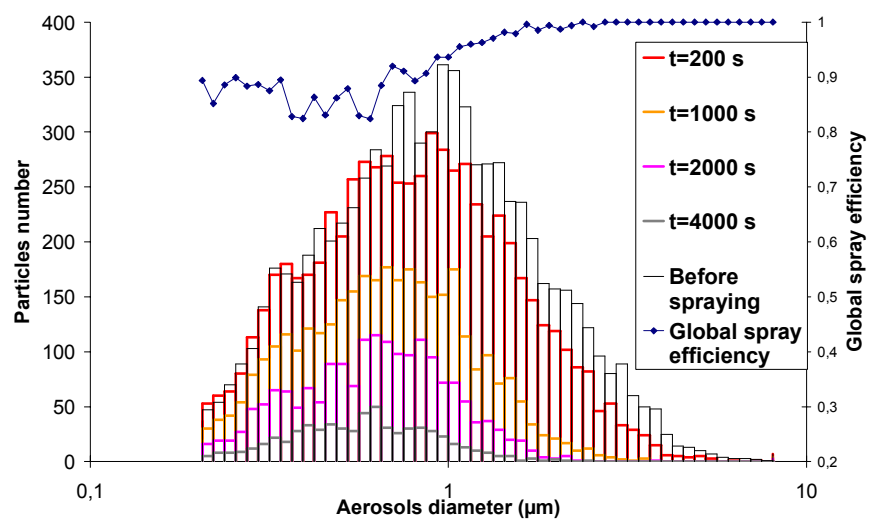

Fig.13 Aerosol size distribution at different time

In this part, we investigate the aerosol removal rate $\left(\lambda_{s}\right)$ and the single droplet collection

efficiency (E) during the test. The single droplet efficiency is defined as the ratio between the aerosol mass collected by a droplet and the aerosol mass present in the swept out volume. We need to measure the global aerosol mass collected by spray droplets at each time step. As aerosol concentration is expected to be different in the spray region and in the dry region, during spray injection, the WELAS granulometer measurement which is a local measurement, can not be used to determine the total aerosol mass present in the gas of the vessel.

On the other hand, before spray activation, the aerosol mass concentration present in the gas $\left[\mathrm{C}_{\text {aerosol }}(0)\right]$ can be determined using WELAS granulometer measurement because the aerosol mass concentration is homogeneous in the gas of the vessel due to mixing induced by steam injection. It is why one can extrapolate the total aerosol mass is the vessel $\left[\mathrm{M}_{\text {aerosol_gas }}(0)\right]$ (Eq. 4) from the local measurement performed with the WELAS granulomoter.

During spray activation, the global aerosol mass collected by spray droplet at each time step $\left[\mathrm{M}_{\text {aerosol_collected }}(\mathrm{t})\right]$ is measured in using the turbidimeter.

The total aerosol mass present in the gas at the instant $t\left(M_{\text {aerosol_gas }}(t)\right.$, Eq. 5) is obtained experimentally in making the difference between the initial aerosol mass present at $\mathrm{t}=0 \mathrm{~s}$ (Eq. 4) and the aerosol mass collected by the spray at the instant $t$ ( $\left.M_{\text {aerosol_collected }}(t)\right)$.

$$
\begin{aligned}
& M_{\text {aerosol_gas }}(0)=C_{\text {aerosol }}(0) \cdot V_{T O S Q A N_{-} \text {vessel }} \\
& M_{\text {aerosol_gas }}(t)=M_{\text {aerosol_gas }}(0)-M_{\text {aerosol_collected }}(t)
\end{aligned}
$$


On the other hand, the total aerosol mass present in the gas at the instant $\mathrm{t}$ can also be defined in using the aerosol removal rate $\lambda_{s}$ by the Eq. 6 .

$$
M_{\text {aerosol_gas }}(t)=C_{\text {aerosol }}(0) \cdot \exp -\left(\lambda_{s} t\right) \cdot V_{\text {TOSQAN_vessel }}
$$

The evolution of the total aerosol mass present in the gas of the vessel (Eq. 5) is presented in Fig. 14.

At spray activation $(t=0 \mathrm{~s})$, the initial total aerosol mass in suspension in the vessel equals $1238 \mathrm{mg}$ which is less than the aerosol mass injected in the vessel before spray activation $(\mathrm{m}=1500 \mathrm{mg})$. This difference may be related to aerosol deposition on vertical walls induced by the development of a wall turbulent boundary layer.

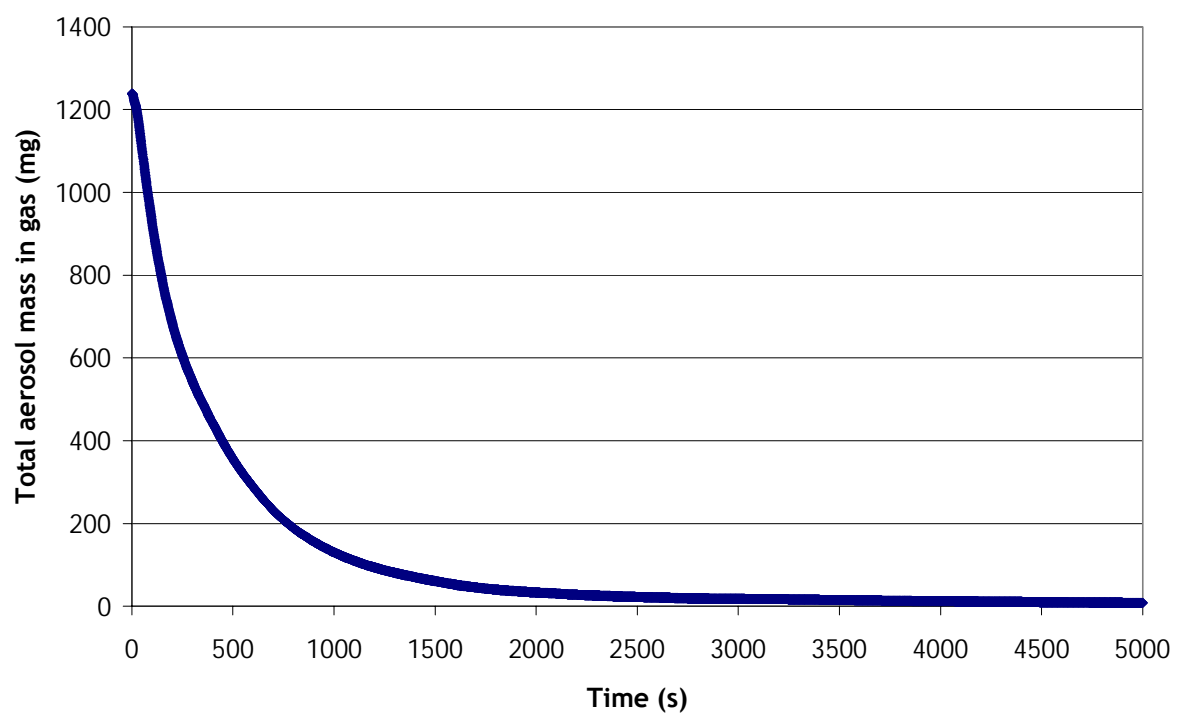

Fig.14. Time evolution of the aerosol mass in the gas of the vessel (mg)

Use of the Postma ${ }^{(14)}$ (Eq. 7) allows computing the single droplet collection efficiency (E) at each time step from the aerosol removal rate $\left(\lambda_{s}\right)$. The Postma relation links the droplet collection efficiency to spray and vessel parameters such as droplet size $\left(\mathrm{D}_{\text {droplet }}\right)$, droplet falling height $(\mathrm{h})$, vessel volume $\left(\mathrm{V}_{\text {TOSQAN_vessel }}\right)$ and water spray mass flow rate $\left(\mathrm{Q}_{\text {spray_volumic }}\right)$.

$\lambda_{s}=\frac{3}{2} \frac{Q_{\text {spray_volumic }} \cdot h}{D_{\text {droplet }} \cdot V_{\text {TOSQAN_vessel }}} \cdot E$

With:

$$
\begin{aligned}
& \mathrm{h}=4 \mathrm{~m} \\
& Q_{\text {spray_volumic }}=30 \cdot 10^{-6} \mathrm{~m}^{3} \mathrm{~s}^{-1} \\
& \mathrm{~V}_{\text {TOSQAN_vessel }}=7 \mathrm{~m}^{3} \\
& \mathrm{D}_{\text {droplet }}=146 \mu \mathrm{m}
\end{aligned}
$$


Some assumptions are necessary to use the Postma relation such as the whole vessel volume is covered by monodispersed spray droplets, and that the aerosol mass concentration is homogeneous in the vessel. For TOSQAN test, according to the spray angle $\left(57^{\circ}\right)$, the sprinkled volume corresponds to $75 \%$ of the vessel volume. The droplet size distribution is not strictly monodispersed, but from the Fig.3, we can see that the droplet size distribution is relatively centred. The aerosol mass concentration is expected to be homogeneous inside the spray region. So, the curve showing the time evolution of the aerosol mass in gas (Fig.14) is fitted from time equal to $200 \mathrm{~s}$ to time equal to $1500 \mathrm{~s}$ to determine the aerosol removal rate $\left(\lambda_{s}\right)$ (Fig.15).

At the time of the spray activation, a transient phase of water draining occurs in the sump bottom and the online turbidimeter measurement can not be directly related to the aerosol mass collected by spray droplets. The duration of the draining phase was determined to be $200 \mathrm{~s}$, and measurements taken during this time period are discarded. At the same time, measurements obtained for $\mathrm{t}>1500 \mathrm{~s}$ are not considered due to the increase of the online turbidimeter accuracy observed for lower aerosol mass concentration presents in draining water.

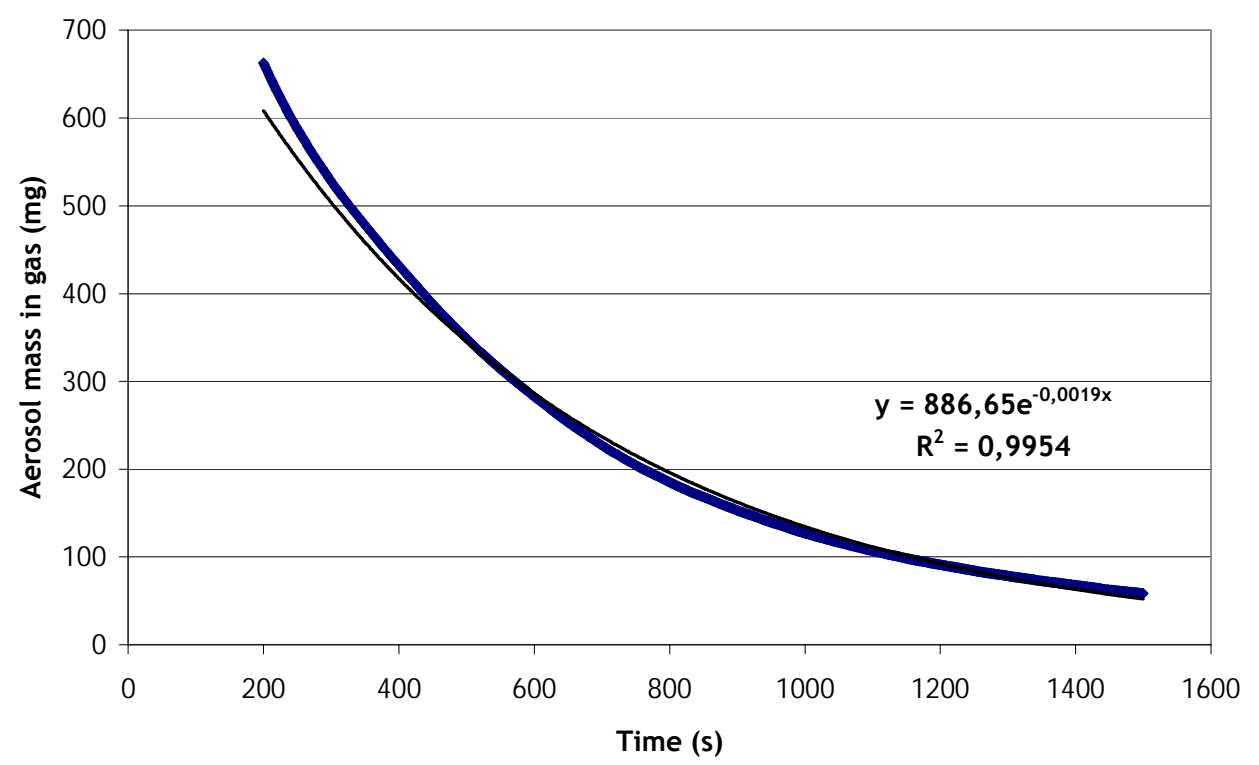

Fig.15. Time evolution of the total aerosol mass present in the gas inside the vessel from $t=200 \mathrm{~s}$ to $\mathrm{t}=1500 \mathrm{~s}$. Determination of aerosol removal rate from the curve fitting

According to the result presented on the Fig.15, the aerosol removal rate is equal to 0.0019 during the period $200 \mathrm{~s}$ to $1500 \mathrm{~s}$. In this condition, the droplet collect efficiency computed with the relation (2) is equal to 0.0108 which is in good agreement between Powers's results for droplet size of $200 \mu \mathrm{m}^{(15)}$ and with Ducret's results ${ }^{(16)}$ for monodisperse droplet size of $280 \mu \mathrm{m}$. Let's point out the fact that Ducret's results were obtained during steady state thermal-hydraulic conditions and aerosol mass concentration in suspension in the CARAIDAS vessel, and the single droplet efficiency is constant during the test, as opposed to the TOSQAN vessel where the aerosol population changes all along the test. 


\section{Conclusion}

Spray tests with aerosol were conducted in the TOSQAN large facility devoted to thermal hydraulic containment studies. Spray tests realized in hot conditions allow us to study the interaction between spray droplets and gaseous mixtures such as air and steam, seeded with aerosol simulating fission products. Advanced instrumentation was developed, implemented and qualified on the TOSQAN facility in order to characterize all the magnitudes required for analysing the effect of spray injection on containment thermal hydraulic conditions and also, the local heat and mass transfers between spray droplets and gas. Detailed measurements such as the droplets velocity, droplet size, aerosol size and concentration, gas volume concentrations, gas temperature and pressure were then performed during the tests. First, an overall analysis was conducted to explain the different phases of the spray test, such as the initial steam overpressure induced by droplets vaporization followed by a strong vessel depressurization due to steam condensation on droplets and convective heat transfer between droplets and gas. The last phase identified is a steady state for which the energy provided to the droplets by the gas is compensated by that provided by the heated walls to the gas. Aerosol removal by spray droplets was studied in order to quantify the global spray collection efficiency and the single droplet collection efficiency. Results show that aerosol which size is above than $2 \mu \mathrm{m}$ are rapidly wash out by the spray. Spray efficiency is less good for smaller aerosol for which droplets collection by mechanical effects has a poor efficiency, according to droplets size. The single droplet collection efficiency was computed of the test. The first results obtained for thermal hydraulic conditions representative of severe accident in the TOSQAN vessel show a good agreement with literature studies. In the next future, spray tests with aerosol will be continued in order to analyse the effect of spray and aerosol parameters on aerosol removal processes.

\section{References}

(1)Fermandjian, J., Comportement des aérosols dans l'enceinte de Confinement, SFRP Meeting on mitigation and confinement of radioactive products in water cooled reactors, Saclay, 1984.

(2)Porcheron, E., Brun, P., Cornet, P., Malet, J., Vendel, J., Optical diagnostics applied for single and multi-phase flow characterization in the TOSQAN facility dedicated for thermal hydraulic containment studies, Proceedings of the NURETH-10, Seoul, 2003.

(3)Auban, O., Malet, J., Brun, P., Brinster, J., Quillico, J., Studer, E., Implementation of gas concentration measurements systems using mass spectrometry in containment thermal hydraulic test facilities: Different approaches for calibration and measurement with steam/air/helium mixtures, Proceedings of the NURETH-10, Seoul, 2003.

(4)Mölter, L. and Keßler, P., Partikelgrößen- und partikelanzahlbestimmung in der außenluft mit einem neuen optischen aerosolpektrometer, Gefahrstoffe Reinhaltung der Luft, Vol. 64, (10), pp. 439-447, 2004.

(5)Bachalo, W.D., Houser, M.J., 1984. Phase/Doppler spray analyzer for simultaneous measurements of drop size and velocity distribution, Optical Engineering, Vol. 23, No. 5, pp. 583-590.

(6)Lemaitre, P., Porcheron, E., Nuboer, A., Grehan, G.,. Interferometric laser imaging development in order to measure droplet size in hostile environment, Proceedings of the ICLASS, Kyoto, 2006. 
(7)Porcheron E., Thause L., Malet J., Cornet P., Brun P., Vendel J., Simultaneous application of spontaneous Raman scattering and LDV, PIV for steam-air flow characterization, Proceedings of the $10^{\text {th }}$ Int. Symposium on Flow Visualization, Kyoto, 2002.

(8)Porcheron, E., Carreau, J.L., Prevost, L., Roger, F., 2002. Effect of gas density injection on assisted cryogenic liquid jet atomization, Atomization \& Sprays, pp. 209-227, Vol. 12.

(9)Haar, L., Gallager, J.S. and Kell, G.S., NBS/NRC Steam Tables, Hemisphere Publishing Corp., New York, 1984.

(10)Marchand, D., Porcheron, E., Lemaitre, P. and Grehan, G., Characterization of the washout of aerosol by spraying water for thermal hydraulic conditions representative of a severe accident in a nuclear reactor containment, ICLASS, Kyoto, 2006.

(11)Rimberg, D. and Peng, Y., Aerosol collection by falling droplets, Air pollution Control and Design Handbook, New York, 1977.

(12)Waldmann, L. and Schmitt, K. H., Thermophoresis and diffusiophoresis of aerosol, C.N. Davies, 1966.

(13)Murata, K., K., Williams, D., C., Tills, J., Griffith, R., O., Gido, R., G., Tadios, E., L., Davis, F., J., Martinez, G. and Washington, K., E., Code Manual for CONTAIN 2.0: A computer Code for Nuclear Reactor Containment Analysis, NUREG/CR-6533, SAND97-1735, Sandia National Laboratories, Albuquerque, New Mexico.

(14)Postma, A. K., Sherry, R. R. and Tam, P. S. (1978) Technological bases for models of spray washout of airborne contaminants in containment vessels. NUREG/CR-0009, Nuclear Regulatory Commission, Office of Nuclear Reactor Regulation, Division of Site Safety and Environmental Analysis, Accident Analysis Branch ; for sale by the National Technical Information Service.

(15)Powers, D. A. and Burson, S. B., A Simplified Model Of Aerosol Removal by Containment Sprays, NUREG/CR-5966, SAND92-2689, 1993.

(16)Ducret, D., Roblot, D. and Vendel, J., Etude analytique du comportement des gouttes et du rabattement des produits de fission par l'aspersion : résultats expérimentaux et modèles, OECD Specialist Meeting On Nuclear Aerosol In Reactor Safety, Cologne, 1998. 